\title{
Comparison of Intravitreal Triamcinolone Treatment and Intravitreal Triamcinolone with Grid Laser Treatment in Patients with Diffuse Diabetic Macular Edema
}

\author{
Hasan Ali Tufan'1, Şengül Özdek², Berati Hasanreisoğlu² \\ 'Department of Ophthalmology, Faculty of Medicine, Çanakkale Onsekiz Mart University, Çanakkale, Turkey \\ ${ }^{2}$ Department of Ophthalmology, Faculty of Medicine, Gazi University, Ankara, Turkey
}

\begin{abstract}
Objective: To compare the efficacy of intravitreal triamcinolone acetonide (IVTA) and IVTA plus macular laser grid photocoagulation therapy in diffuse diabetic macular edema (DME).

Material and Methods: Sixteen patients affected by diffuse DME were retrospectively evaulated. Patients were divided into two groups: control group (IVTA injection) and laser group (IVTA plus grid laser). Main outcomes were best corrected visual aquity (BCVA) and central macular thickness (CMT) at the $3^{\text {rd }}$ and $6^{\text {th }}$ months of treatment. IVTA associated complications and reinjection necessity were assessed.

Results: Our study comprised 18 eyes of 16 patients. The baseline BCVA and CMT were $0.93 \pm 0.45$ and $530 \pm 136 \mu m$ for the control and $1.02 \pm 0.52$ and $509 \pm 177 \mu \mathrm{m}$ for the laser group respectively. Posttreatment BCVA at the $3^{\text {rd }}$ and $6^{\text {th }}$ month were $0.73 \pm 0.4$ and $0.75 \pm 0.45$ for control and $0.98 \pm 0.44$ and $1.04 \pm 0.4$ for laser group respectively ( $p>0.05$ for all). CMT values at the $3^{\text {rd }}$ and $6^{\text {th }}$ months were $260 \pm 174 \mu \mathrm{m}(p=0.008)$ and $362 \pm 163 \mu \mathrm{m}$ ( $\left.p=0.05\right)$ for control and $331 \pm 161 \mu \mathrm{m}(\mathrm{p}=0.05)$ and $388 \pm 215 \mu \mathrm{m}(\mathrm{p}>0.05)$ for laser groups. $55 \%$ of control and $66 \%$ of laser groups needed reinjection with an avarage of $7 \pm 4$ months after the first injection. $22 \%$ cataract progression and $33 \%$ intraocular pressure elevation were noted.
\end{abstract}

Conclusion: Macular grid laser photocoagulation after IVTA does not have beneficial effects for diffuse DME.

Key Words: Diabetic macular edema (DME), intravitreal triamcinolone (IVTA), grid laser

Received: 16.08.2011 Accepted: 03.11.2011

\section{Introduction}

Macular edema is the primary cause of visual impairment in diabetic patients (1). Laser photocoagulation remains to be the gold standard treatment for most eyes with diabetic macular edema (DME) (2). However, $12 \%$ of patients are still refractory to laser photocoagulation which exhibits a loss of three or more ETDRS (Early Treatment Diabetic Retinopathy Study) lines at a 3-year-follow up interval (3). DME, especially DME of the diffuse type, remains refractory to appropriate focal or grid laser treatments, and this has drawn attention to alternative treatments for diffuse DME (4). Among alternative treatments currently under investigation, intravitreal treatment with both steroids and antivascular endothelial growth factor agents has been reported to be efficacious (5-7). Intravitreal triamcinolone acetonide (IVTA) has recently been popular for the treatment of diffuse DME (8). Necessity of repeated injection and steroid related ocular complications (cataract, glaucoma and ocular toxicity) are the main problems of IVTA $(9,10)$. Although laser photocoagulation remains the gold standard treatment for DME (11), studies have recently been carried out on the use of combined mo- dality. It is known that the more swollen the macula, the more laser energy is needed at the level of the retinal pigment epithelium. Thus, injection of IVTA before laser treatment may strengthen the effectivity of laser photocoagulation, which may result in a better outcome. It is also known that destruction of the RPE/photoreceptor complex by laser treatment results in improved oxygenation of the inner retina and reduced leakage, which may prevent the recurrence of the edema (12).

In this study, we attempted to determine whether macular grid laser photocoagulation after IVTA might be helpful in the maintenance of anatomical and functional success after IVTA in diffuse macular edema. The question of whether grid laser treatment decrease the reinjection frequency is also evaluated.

\section{Material and Methods}

In this study, 18 eyes of 16 diabetic patients, all of whom had been diagnosed with diffuse DME and treated with IVTA injection, were retrospectively evaulated between the years 2003 and 2007. The included eyes were divided into 2 groups: the laser group and the control group. 9 eyes were the control group, which were treated only with IVTA. The other 9 
eyes were the laser group which were treated with IVTA and macular grid photocoagulation after 1 month. Patients who had received a complete ocular examination, including bestcorrected visual acuity on a Snellen chart; applanation tonometry; slitlamp examination; and dilated fundus examination using biomicroscopy, OCT (optic coherence tomography) and fundus fluorescein angiography at the time of diagnosis, were included. Diffuse DME had to be diagnosed by the criteria which were a zone, or zones, of retinal thickening, 1 disc area or larger at any part within 1 disc diameter of the center of the macula on biomicroscopy, reduction in the reflectivity of the outer layer and/or subfoveal fluid collection on OCT and diffuse fluorescein leakage on fluorescein angiography. Patients who had glaucoma or a history of intraocular surgery were excluded. Indicators for functional and anatomical success were improvement in best corrected visual acuity (BCVA) and the central macular thickness (CMT) respectively. BCVA and CMT values were noted at the time of diagnosis, 3 months and 6 months after IVTA. In order to assess the incidence of complication, cataract and increase of intraocular pressure were also noted. Exclusion criteria were a history of corticosteroidresponsive intraocular pressure (IOP) rise, intraocular surgery within 6 months, and the other ocular diseases (uveitis, retinal vascular occlusion) that may cause macular edema. The corrected visual acuities were transformed to Logarithm of the Minimum Angle of Resolution (logMAR) for statistical analysis. Statistical analyses utilized SPSS 12.0.1 (SPSS Inc., Chicago, IL, USA) for Windows. CMT, BCVA values of the two groups were compared with the student t-test or Mann-Whitney Utest where appropriate. The level of statistical significance was set at $p<0.05$.

\section{Results}

Our study comprised 18 eyes of 16 patients (10 females, 8 males) aged between 42 and 80 years with an avarage of 61.2 \pm 10.7. Mean follow-up time was $17.1 \pm 6.3$ (6-40) months. The baseline BCVA and CMT were $0.93 \pm 0.45$ and $530 \pm 136$ $\mu \mathrm{m}$ for the control group and $1.02 \pm 0.52$ and $509 \pm 177 \mu \mathrm{m}$ for the laser group respectively. There was no statistically significant difference between the two groups for baseline values.

BCVA and CMT values of the control group are presented in Table 1 and 2. In the control group (IVTA), post treatment BCVA improved to $0.73 \pm 0.4$ at the $3^{\text {rd }}$ month and then deteriorated to $0.75 \pm 0.45$ at the $6^{\text {th }}$ month. CMT reduced to $260 \pm 174 \mu \mathrm{m}$ at the $3^{\text {rd }}$ month and stayed stable with a value of $362 \pm 163 \mu \mathrm{m}$ at the $6^{\text {th }}$ month. Thus, a statistically non-significant improvement in BCVA $(p=0.06)$ was noted at the $3^{\text {rd }}$ month and stayed stable at the $6^{\text {th }}$ month. CMT decreased by $49 \%$ at the $3^{\text {rd }}$ month $(p=0.008)$ and the effect maintained by the end of 6 months $(p=0.05)$.

BCVA and CMT values of control group are presented in Table 1 and 2. In the laser group (grid laser treatment one month after IVTA), post treatment BCVA improved to $0.98 \pm 0.44$ at the $3^{\text {rd }}$ month and the effect was nullified by the end of 6 months with a value of $1.04 \pm 0.4$, both being statistically non-significant (>0.05). CMT was reduced to $331 \pm 161 \mu \mathrm{m}$
Table 1. Statistical comparisons of BCVA values before treatment, $3^{\text {rd }}$ and $6^{\text {th }}$ months after treatment in both groups

\begin{tabular}{|c|c|c|c|c|}
\hline Group & $\begin{array}{c}\text { BCVA } \\
\text { LogMAR } \\
\text { (Before } \\
\text { Treatment) }\end{array}$ & $\begin{array}{c}\text { BCVA } \\
\text { LogMAR } \\
3^{\text {rd }} \\
\text { month }\end{array}$ & $\begin{array}{c}\text { BCVA } \\
\text { LogMAR } \\
6^{\text {th }} \\
\text { month }\end{array}$ & $\underset{\text { values }}{p}$ \\
\hline IVTA $^{\star \star \star}$ & $0.93 \pm 0.45$ & $0.73 \pm 0.4$ & $0.75 \pm 0.45$ & $a$ \\
\hline IVTA+Grid laser & $1.02 \pm 0.52$ & $0.98 \pm 0.44$ & $1.04 \pm 0.4$ & $b$ \\
\hline
\end{tabular}

a. Before treatment vs. $3^{\text {rd }}$ month: $p>0.05$. Before treatment vs. $6^{\text {th }}$ month: $p>0.05$ b. Before treatment vs. $3^{\text {rd }}$ month: $p>0.05$. Before treatment vs. $6^{\text {th }}$ month: $p>0.05$ *BCVA: Best corrected visual acuity.

**LogMAR: Logarithm of the Minimum Angle of Resolution

***IVTA: Intravitreal triamcinolone acetonide

Table 2. Statistical comparisons of $\mathrm{CMT}^{\star}$ values before treatment, $3^{\text {rd }}$ and $6^{\text {th }}$ months after treatment in both groups

\begin{tabular}{|lcccc|}
\hline Group & CMT $(\mu \mathrm{m})$ & CMT $(\mu \mathrm{m})$ & CMT $(\mu \mathrm{m})$ & $p$ \\
& Before Treatment & $3^{\text {rd }}$ month & $6^{\text {th }}$ month values \\
\hline IVTA & $530 \pm 136$ & $260 \pm 174$ & $362 \pm 163$ & $a$ \\
IVTA+Grid laser & $509 \pm 177$ & $331 \pm 161$ & $1.04 \pm 0.4$ & $b$ \\
\hline
\end{tabular}

a. Before treatment vs. $3^{\text {rd }}$ month: $p=0.008$. Before treatment vs. $6^{\text {th }}$ month: $p=0.05$ b. Before treatment vs. $3^{\text {rd }}$ month: $p=0.05$. Before treatment vs. $6^{\text {th }}$ month: $p>0.05$ *CMT: Central Macular Thickness

**IVTA: Intravitreal triamcinolone acetonide

at the $3^{\text {rd }}$ month with a recurrence of edema which was $388 \pm 215 \mu \mathrm{m}$ at the $6^{\text {th }}$ month. CMT was reduced $65 \%$ at the $3^{\text {rd }}$ month $(p=0.05)$ and the effect was nullified by the end of 6 months (>0.05).

Five of 9 patients (55\%) in the control group and 6 of 9 patients $(66 \%)$ in the laser group needed reinjection $7 \pm 4$ month after the first injection.

Injection related complication did not occur. Cataract progression was noted in two patients in each group $(22 \%$ in total). Six patients (33\%), three in each group, developed a temporary rise in IOP, which was well controlled on medication. None of the patients needed cataract or glaucoma surgery during the follow-up period.

\section{Discussion}

Macular edema is the leading cause of visual loss in diabetic patients (1). Laser photocoagulation has been considered to be the gold standard treatment for DME (2). However, DME, especially DME of the diffuse type, may persist or recur despite appropriate laser therapy (4). In recent years, application of triamcinolone acetonide via either an intravitreal or a posterior sub-Tenon's route has yielded promising results in the treatment of diffuse DME $(8,13)$. Their main limitation is the short term duration of action, which necessitates repeated injections and complications related to both steroid (cataract, glaucoma) and injection (endophthalmitis, retinal detachment).

Previous studies have shown both superiority of combined modality over IVTA alone (14) as well as equal outcomes with IVTA, laser or combined modality at the $6^{\text {th }}$ month of the followup (15). In this study, we speculated that there is a synergistic effect between IVTA and laser photocoagulation for DME. 
In our study, altough it was not statistically significant, a BCVA improvement was seen at the $3^{\text {rd }}$ and $6^{\text {th }}$ months after IVTA injection. A statistically significant CMT reduction was obtained at the $3^{\text {rd }}$ month and this effect continued for 6 months. Previous reports have demonstrated improvements in the visual acuity and the alleviation of diffuse macular edema after IVTA $(13,16)$.

The mechanism of corticosteroids in the treatment of macular edema may rely on their ability to inhibit the arachidonic acid pathway and downregulate the production of vascular endothelial growth factor which results in a reduction of vascular permeability $(3,17,18)$. In contrast to previous studies, both anatomical and functional success continued for 6 months after IVTA injection (13). DME relapse represents a major drawback of IVTA $(9,10)$. Not surprisingly, in our study, $55 \%$ of patients needed reinjection, with an average of 7 months after IVTA injection. Both the reinjection rate and interval were similar to those in previous studies (19).

In our study, the laser group (grid laser treatment one month after IVTA) demonstrated posttreatment BCVA improvement at both the $3^{\text {rd }}$ and $6^{\text {th }}$ month controls with a statistically non-significant change. A statistically significant CMT reduction was obtained at the $3^{\text {rd }}$ month and this effect was nullified by the end of 6 months. It has been noted that the change in CMT is a poor surrogate marker for change in VA in eyes with $\mathrm{DME}$, probably because of irreversible structural damages which is difficult to measure (20). Previous studies have demonstrated that grid laser photocoagulation applied to areas of diffuse macular edema results in a substantial reduction of the risk of visual loss in eyes with $\operatorname{DME}(4,21-23)$. We obtained limited anatomical and functional success which we would not expect. Diffuse DME represents an advanced stage of diabetic retinopathy which originates from generalized breakdown of the blood-retinal barrier. Thus, the effects of laser on the retinal vascular endothelium and photoreceptors are not to be expected under such circumstances. It has been seen that diffuse DME is associated with poor prognoses despite additional grid laser photocoagulation, and these data are supported by previous studies $(4,21)$. Lee and Olk (4) demonstrated reduced visual acuity in $24.6 \%$ of eyes after grid laser photocoagulation for diffuse DME.

In our study, it was also noted that additional grid laser application neither reduces the reinjection necessity $(66 \%)$ nor shortens the reinjection interval.

Steroid-related cataract progression and intraocular pressure elavation were seen at a rate similar to those in previous reports $(9,24)$.

Being retrospective and the involvement of a relatively small number of patients were the main limitations of our study. Visual acuity was measured on a Snellen chart, as opposed to the more standardized chart from the Early Treatment Diabetic Retinopathy Study.

\section{Conclusion}

Macular grid laser photocoagulation after IVTA does not have beneficial effects on diffuse DME. Considering the complications of the macular laser photocoagulation, only IVTA in- jection may be the true therapeutic approach for diffuse DME. Although IVTA has been reserved for DME refractory to laser photocoagulation, we consider that it would be a primary treatment for diffuse DME. Further studies with a randomized, prospective and longer follow-up period with a large number of patients may provide more knowledge about diffuse DME.

\section{Conflict of Interest}

No conflict of interest was declared by the authors.

\section{References}

1. Klein R, Klein BE, Moss SE, Davis MD, DeMets DL. The Wisconsin Epidemiologic Study of Diabetic Retinopathy, IV: diabetic macular edema. Ophthalmology 1984;91:1464-74.

2. Diabetic Retinopathy Clinical Research Network Ophthalmology. A randomized trial comparing intravitreal triamcinolone acetonide and focal/grid photocoagulation for diabetic macular edema. Ophthalmology 2008;115:1447-9. [CrossRef]

3. Bresnick GH. Diabetic maculopathy: a critical review highlighting diffuse macularedema. Ophthalmology 1983;90:1301-17.

4. Lee CM, Olk RJ. Modified grid laser photocoagulation for diffuse diabetic macular edema: long term visual results. Ophthalmology 1991;98:1594-602.

5. Sutter FK, Simpson JM, Gillies MC. Intravitreal triamcinolone for diabetic macular edema that persists after laser treatment: threemonth efficacy and safety results of a prospective, randomized, double-masked, placebo-controlled clinical trial. Ophthalmology 2004;111:2044-9. [CrossRef]

6. Kuppermann BD, Blumenkranz MS, Haller JA, Williams GA, Weinberg DV, Chou C, et al. Dexamethasone DDS Phase II Study Group. Randomized controlled study of an intravitreous dexamethasone drug delivery system in patients with persistent macular edema. Arch Ophthalmol 2007;125:309-17. [CrossRef]

7. Arevalo JF, Fromow-Guerra J, Quiroz-Mercado H. Pan-American Collaborative Retina Study Group. Primary intravitreal bevacizumab (Avastin) for diabetic macular edema: results from the Pan-American Collaborative Retina Study Group at 6-month followup. Ophthalmology. 2007;114:743-75. [CrossRef]

8. Massin P, Audren F, Haouchine B, Erginay A, Bergmann JF, Benosman $\mathrm{R}$, et al. Intravitreal triamcinolone acetonide for diabetic macular edema: preliminary results of a prospective controlled trial. Ophthalmology 2004;111:218-25. [CrossRef]

9. Jonas JB, Kreissig I, Degenring RF. Intraocular pressure after intravitreal injection of triamcinolone acetonide. $\mathrm{Br} \mathrm{J}$ Ophthalmol 2003;87:24-7. [CrossRef]

10. Yoshikawa K, Kotake S, Ichiishi A, Sasamoto Y, Kosaka S, Matsuda $\mathrm{H}$. Posterior sub-Tenon injections of repository corticosteroids in uveitis patients with cystoid macular edema. Jpn J Ophthalmol 1995;39:71-6.

11. Diabetic Retinopathy Clinical Research Network Ophthalmology. A randomized trial comparing intravitreal triamcinolone acetonide and focal/grid photocoagulation for diabetic macular edema. Ophthalmology 2008;115:1447-9. [CrossRef]

12. Gottfredsdóttir MS, Stefánsson E, Jónasson F, Gíslason I. Retinal vasoconstriction after laser treatment for diabetic macular edema. Am J Ophthalmol. 1993;115:64-7.

13. Martidis A, Duker JS, Greenberg PB, Rogers AH, Puliafito CA, Reichel $\mathrm{E}$, et al. Intravitreal triamcinolone for refractory diabetic macular edema. Ophthalmology 2002;109:920-7. [CrossRef] 
14. Kang SW, Sa HS, Cho HY. Macular grid photocoagulation after intravitreal triamcinolone acetonide for diffuse diabetic macular edema. Arch Ophthalmol 2006;124:653-8. [CrossRef]

15. Lam DS, Chan CK, Mohamed S, Lai TY, Lee VY, Liu DT, Li KK, et al. Intravitreal Triamcinolone plus sequential grid laser versus Triamcinolone or laser alone for treating diabetic macular edema: Sixmonth outcomes. Ophthalmology 2007;114:2162-7. [CrossRef]

16. Jonas JB, So"fker A. Intraocular injection of crystalline cortisone as adjunctive treatment of diabetic macular edema. Am J Ophthalmol 2001;132:425-7. [CrossRef]

17. Wilson CA, Berkowitz BA, Sato Y, Ando N, Handa JT, de Juan E Jr. Treatment with intravitreal steroid reduces blood-retinal barrier breakdown due to retinal photocoagulation. Arch Ophthalmol 1992;110:1155-9. [CrossRef]

18. Sakamoto T, Miyazaki M, Hisatomi T, Nakamura T, Ueno A, Itaya $K$, et al. Triamcinolone-assisted pars plana vitrectomy improves the surgical procedures and decreases the postoperative bloodocular barrier breakdown. Graefes Arch Clin Exp Ophthalmol 2002;240:423-9. [CrossRef]
19. Jonas JB, Degenring RF, Kamppeter BA, Kreissig I, Akkoyun I. Duration of the effect of intravitreal triamcinolone acetonide as treatment of diffuse diabetic macular edema. Am J Ophthalmol 2004;138:158-60. [CrossRef]

20. Larsson J, Zhu M, Sutter F, Gillies MC. Relation between reduction of foveal thickness and visual acuity in diabetic macular edema treated with intravitreal triamcinolone. Am J Ophthalmol 2005; 139:802-6. [CrossRef]

21. Photocoagulation for diabetic macular edema: Early Treatment Diabetic Retinopathy Study report number 1. Arch Ophthalmol 1985; 103:1796-806 [CrossRef]

22. Treatment techniques and clinical guidelines for photocoagulation of diabetic macular edema: Early Treatment Diabetic Retinopathy Study report number 2. Ophthalmology 1987;94:761-74.

23. Photocoagulation for diabetic macular edema: Early Treatment Diabetic Retinopathy Study report number 4. Int Ophthalmol Clin 1987;27:265-72. [CrossRef]

24. Özkırış A, Erkılıç K. Complications of intravitreal injection of triamcinolone acetonide. Can J Ophthalmol 2005;40:63-8. 